\title{
CONDUCTION PROPERTIES OF CENTRAL DEMYELINATED AND REMYELINATED AXONS, AND THEIR RELATION TO SYMPTOM PRODUCTION IN DEMYELINATING DISORDERS
}

\author{
KENNETH J. SMITH \\ London
}

\begin{abstract}
SUMMARY
The conduction properties of central demyelinated and remyelinated axons are discussed, and related to the expression of symptoms in central demyelinating disease. The mechanisms underlying the block and restoration of conduction in segmentally demyelinated axons are described, together with the range of deficits expressed by the conducting axons. These abnormalities are related to clinical relapses and remissions, and to the phenomena of weakness, fatigue, the temperature sensitivity of symptoms, and the generation of 'positive' symptoms (e.g. Uhthoff's and Lhermitte's symptoms). The potential role of circulating 'blocking factors' in the symptomatology of central demyelinating disease is examined, and some approaches are advanced for the symptomatic therapy of such diseases.
\end{abstract}

\section{INTRODUCTION}

Demyelination of central nervous system (CNS) axons is the most prominent morphological characteristic of the lesions of disorders such as multiple sclerosis, optic neuritis and acute disseminated encephalomyelitis, and it is believed that many of the symptoms associated with these disorders are directly attributable to conduction disturbances caused by the myelin loss. This review is primarily concerned with the conduction deficits of experimentally demyelinated CNS axons, and the symptoms which may be expected to arise from these deficits. The review focusses on axons in experimental demyelinating lesions, since here the morphology of the affected axons can usually be determined with some certainty, whereas in human disease morphological changes can rarely be studied.

\section{CONDUCTION BLOCK}

The first conduction abnormality to be reliably described

Correspondence to: Dr K. J. Smith, Department of Neurology, United Medical and Dental Schools of Guy's and St Thomas' Hospitals, Guy's Campus, St Thomas Street, London SE1 9RT, UK. in experimentally demyelinated central axons was the complete block of conduction (Fig. 1C, D), ${ }^{1}$ and this remains the most striking feature of conduction in many segmentally demyelinated central axons when examined at body temperature. Conduction block is also a major cause of the most devastating symptoms of multiple sclerosis, such as paralysis and blindness. ${ }^{2-6}$

McDonald and Sears' landmark study of conduction in demyelinated CNS axons employed the central demyelinating lesion induced by the injection of diphtheria toxin into the cat dorsal columns, ${ }^{7-9}$ and although the degree of demyelination of the affected axons in this lesion is uncertain (see below) several other studies have now confirmed that conduction block is the dominant feature where demyelination is largely segmental in character, i.e. where myelin is lost in units of complete internodes. Such lesions include those induced by the detergent-like substance lysophosphatidyl choline (LPC, also known as lysolecithin $),{ }^{10,11}$ the nucleic acid chelating agent ethidium bromide $(\mathrm{EBr})^{12}$ and the autoimmune disease experimental allergic encephalomyelitis (EAE). ${ }^{13}$ Conduction block was also described in some earlier accounts, ${ }^{14-16}$ but confidence in these data is weakened by the uncertainty as to whether the blocked axons were truly demyelinated or were undergoing degeneration (for discussion see McDonald and Sears ${ }^{17}$ ). Demyelination seems only to impair conduction at the site of the lesion, for conduction continues in an apparently normal manner along the morphologically unaffected portions of the axon on either side. ${ }^{1,17}$ Conduction block is also particularly prominent when the axons are examined at body temperature and above (see Effects of Temperature below).

On theoretical grounds, the likelihood that demyelination will result in conduction block is related to the degree of demyelination present, particularly at the paranodes. Thus conduction may be expected to continue, albeit with some reduction in velocity and security, where demyelination is restricted to loss of some but not all of the 


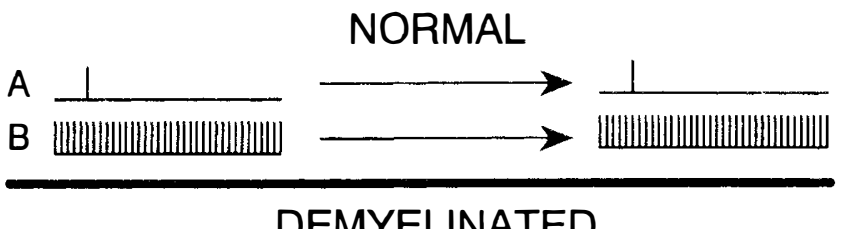

DEMYELINATED
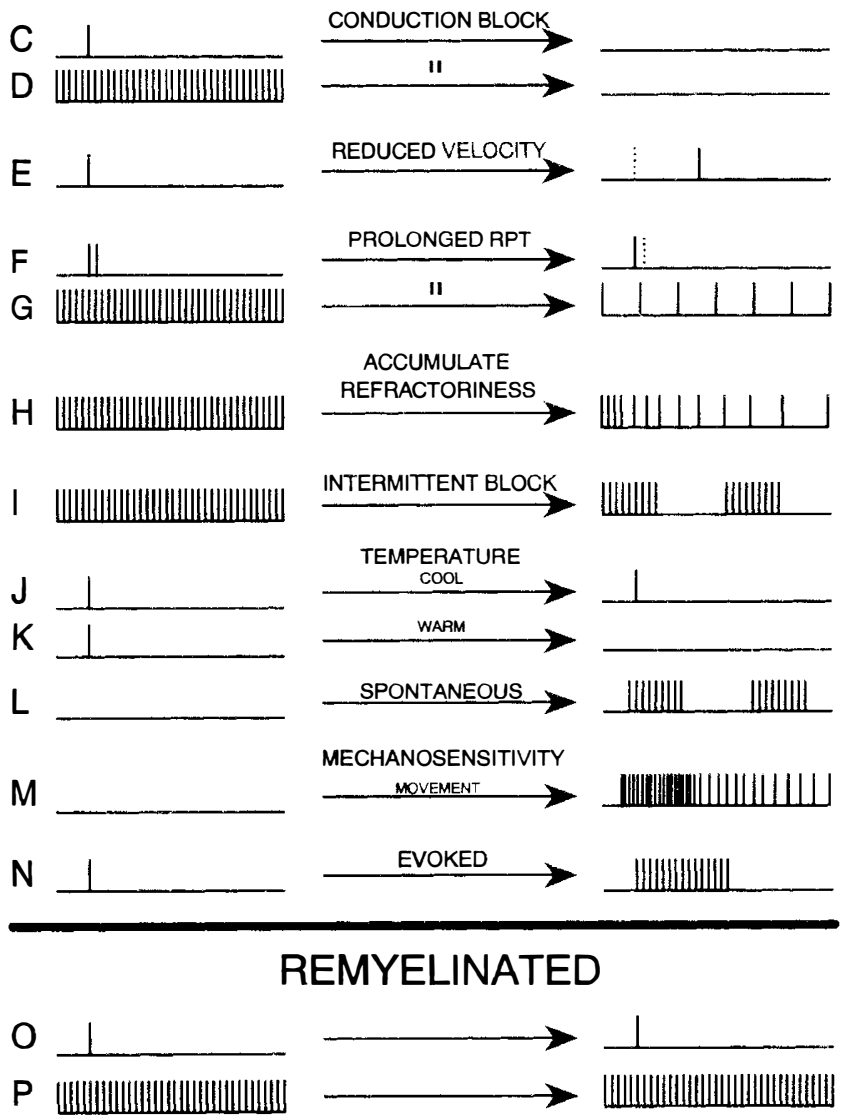

Fig. 1. Schematic representation of the conduction properties of normal, demyelinated and remyelinated central axons. The pattern of impulses entering the site of a lesion is shown on the left, and the resulting pattern leaving the lesion is shown on the right. Normal axons faithfully transmit both single impulses $(A)$ and impulse trains $(B)$. However, sites of demvel ination initially cause conduction block to both single impulses $(C)$ and trains of impulses $(D)$. Where the demyelinated axons later acquire the ability to conduct through the lesion it is with a reduced velocity (E) and a prolonged refractory period of transmission (RPT), i.e. the second impulse of a closely spaced pair may fail to be transmitted $(F)$ and a rapid train of impulses mav be transformed to a low-frequency train due to failure of the lesion to transmit all the impulses $(G)$. With repeated activation demvelinated axons can become progressively less able to conduct closely spaced impulses $(H)$, and may exhibit intermittent periods of complete conduction block (I). Transmission along demyelinated axons is markedly affected by temperature changes, such that cooling promotes successful conduction ( $J$, $K$ ). Demyelinated axons can generate long trains of impulses in the absence of any deliberate stimulus $(L)$, and can also generate trains of impulses in response to deformation (M). Single conducted impulses can provoke the generation of other, ectopic impulses $(N)$. The conduction deficits associated with demyelination are almost entirely reversed by remyelination $(O, P)$.

myelin lamellae (partial-thickness demyelination), or to very limited paranodal widening. ${ }^{18}$ However, where demyelination is more extensive, and certainly where it is segmental, the presence of conduction block becomes much more likely. Indeed, conduction block may be inevitable in newly segmentally demyelinated axons since there is normally only a relatively low $\left(<25 / \mu \mathrm{m}^{2}\right)$ sodium channel density beneath the myelin sheath (the channels expressed by myelinated axons are the subject of an excellent recent review by Waxman and Ritchie ${ }^{19}$ (see also Ritchie and $\operatorname{Rogart}^{20}$ and Shrager ${ }^{21}$ ); and so, initially at least, demyelination must expose axolemma ill-equipped for conduction of nerve impulses. However, Waxman's group have noted that conduction can occur in premyelinated optic nerve axons where the sodium channel density is also low (only $2 / \mu \mathrm{m}^{2}$ ), ${ }^{2-2}$ raising the possibility that even some freshly demyelinated axons may be able to conduct. ${ }^{19.23}$ This is an interesting possibility, but our experience is that conduction is routinely blocked in recently segmentally demyelinated axons. However, it may be significant that our experience is limited to the relatively large-diameter axons of the dorsal column, since conduction is probably favoured by a small axon diameter. ${ }^{23.24}$ It is thus possible that conduction may occur in, say, the recently segmentally demyelinated axons of the optic nerve, although such an event awaits description.

Although newly segmentally demyelinated axons typically exhibit conduction block, it does not necessarily follow that the demyelinated axolemma is inexcitable, because it may simply not be excited. In a normal myelinated axon. conduction proceeds by the excitation of each node of Ranvier in sequence, due to the spread of local currents generated by the preceding node (Fig. 2). This excitation is facilitated by the presence of the myelin sheath, which reduces the lateral flow of current by virtue of its high resistance, and facilitates the longitudinal flow of current by reducing the membrane capacitance.* The presence of the myelin sheath also focusses most of the local current specifically to the very small area of axolemma at the node, and it is the outflow of current there which depolarises across the nodal axolemma to its firing threshold. At this time the nodal voltage-sensitive sodium channels open, and the ensuing influx of sodium ions generates another local current which serves to depolarise the

*The cell membrane is an insulator which separates conducting solutions which bathe it on either side. Since the inside of the cell is negative with respect to the outside (i.e. the resting potential) there is a tendency for negative charges to line up on the inside of the membrane and for these to attract positive charges from the bathing solution to line up along the outer surface of the membrane: this arrangement of charges separated by an insulator constitutes a capacitor. Because cell membranes are very thin the charges are physically close to each other and so they attract each other quite tightly. For the membrane to the depolarised and the capacitor discharged. energy (current) is required and the quantity of current is proportional to the number of charges on the membrane. This measure is, in turn. related to the area of the capacitor and to the distance separating the potentials (the smaller the distance the more charges will be attracted and the greater will be the current required to depolarise the membrane). In myelinated axons, the presence of a bulky myelin sheath along the internode substantially reduces the internodal membrane capacitance since the myelin physically separates the charged particles from each other. Removal of the myelin by demyelination results in a dramatic increase in the area of exposed axolemma, and a decrease in the distance of separation, and this increases the current required to depolarise the membrane, thereby decreasing the safety factor for conduction. Readers interested in a more fundamental account of membrane capacitance are referred to a text by Hille. ${ }^{194}$ 
A

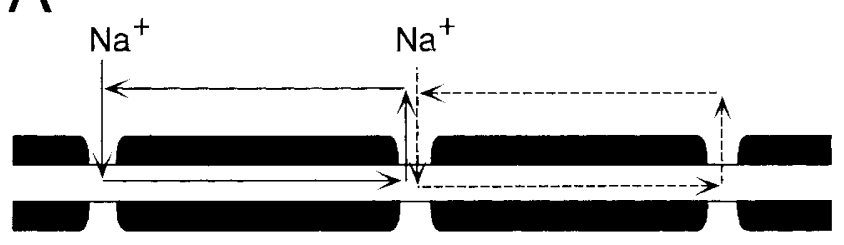

B

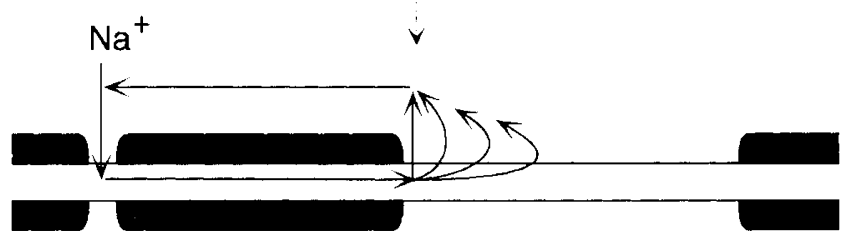

Fig. 2. Diagrams showing the flow of local currents generated by the influx of sodium ions at activated nodes of Ranvier in normal (A) and demyel inated $(B)$ axons. (B) The safety factor for transmission at the demyelinated internode is reduced because (i) the density of outward (depolarising) current is decreased since the current is no longer restricted to the narrow nod al gap, and (ii) the capacitance of the axolemmal membrane is substantially increased by the absence of myelin, requiring a greaterflow of current to depolarise the axon to its firing threshold. For further explanation, see text.

next node in line. ${ }^{25,26}$ It follows that for conduction to proceed across a demyelinated internode, the demyelinated axolemma must be excited by the flow of local currents generated by the action potential formed at the node preceding the demyelinated region. To understand how demyelination affects the flow of local currents it is helpful to consider the 'safety factor' for conduction from node to node: ${ }^{27}$

Safety factor for conduction $=$

Current available to depolarise a node

Current necessary to depolarise the node

In normal axons the safety factor may be as high as $5-7,{ }^{25,27}$ but in demyelinated axons the safety factor is typically reduced to near unity. If the safety factor is fractionally above 1, conduction will continue (albeit with a reduced velocity, etc.) and there may be few symptoms, but if the safety factor is fractionally below 1 then conduction will be blocked and symptoms may be expected. Many multiple sclerosis (MS) patients appear to have large numbers of demyelinated axons with a safety factor near unity, and so even very small changes in the safety factor for conduction can have profound consequences on the severity of the neurological deficit.

The reduced safety factor associated with demyelination arises primarily from two factors. First, the loss of the myelin means that the local currents are no longer funnelled specifically to the small area of nodal axolemma, but rather become dissipated over a larger area of the demyelinated internode. Consequently the current available to depolarise any given area of membrane is reduced, and the safety factor is reduced. Second, the uncovering of a large area of axolemma by demyelination results in a large increase in the membrane capacitance of the demyelinated internode, and therefore a proportionately larger current is required to depolarise the membrane, again reducing the safety factor. In fact the geometry of the internode before the demyelinated stretch, and of the demyelinated segment itself, may mean that the safety factor is so low that conduction in some demyelinated axons would inevitably be blocked even if the demyelinated axolemma were excitable.

These concepts are discussed further elsewhere, and are sometimes grouped under the concept of an impedence mismatch' at the site of demyelination ${ }^{28-31}$ (see also Rasminsky et al. ${ }^{32}$ and Smith et al. ${ }^{33}$ ). However, although conduction might inevitably be blocked in some axons, it is now known that, with time, conduction can be restored along central demyelinated axons (see next section), and thus while impedance mismatch must occur it cannot be an insuperable barrier to conduction in all axons.

However, the degree of demyelination is only one of several factors influencing the presence or absence of conduction block. Other factors are the time which has elapsed since demyelination was established, the geometry of the internode preceding the demyelinated stretch, the temperature (see Effects of Temperature), and properties of the previously internodal axolemma.

The interval since the demyelination was established is important since it seems that although freshly demyelinated axons routinely exhibit conduction block, the axons can adapt to the demyelinated state such that conduction may eventually be restored. Certainly, in the segmental demyelinating lesion induced by the intraspinal injection of ethidium bromide ${ }^{34}$ there is an initial period of conduction block which persists for approximately 2 weeks after segmental demyelination is established, and only then is there the appearance of appreciable numbers of demyelinated axons which conduct successfully through the lesion (P. A. Felts and K. J. Smith, unpublished observations). The precise changes which occur during the 2 week period are not known, but probably include an increase in the sodium channel density along the demyelinated axolemma, ${ }^{24.33}$ and the development of contacts between the axons and glial cell processes. ${ }^{35-38}$

The dimensions of the internode(s) preceding the demyelinated region are important since the safety factor for conduction will be increased if this internode is relatively short so that the driving node is relatively close to the demyelinated axolemma: ${ }^{28}$ a short internode preceding the demyelinated region may be able to compensate for other factors which may not be optimal for conduction in a particular axon. The properties of the demyelinated axolemma are of paramount importance since conduction cannot occur across the length of a segmentally demyelinated internode unless the axolemma actively propagates the impulse: however, the properties of this axolemma are largely unknown. The relatively low density of sodium channels along demyelinated axolemma has already been discussed, but there are also likely to be important changes in the density, types and distribution of potassium chan- 
nels, electrogenic pumps and ion exchangers (reviewed in Waxman and Ritchie ${ }^{19}$ ).

\section{RESTORATION OF CONDUCTION IN DEMYELINATED AXONS}

Although McDonald and Sears found that conduction was typically blocked in axons passing through larger demyelinating lesions $\left(>5 \mathrm{~mm}\right.$ in length), ${ }^{1.17 .39}$ they found that conduction continued in some axons passing through smaller lesions. ${ }^{17.39}$ The conduction was not normal (see below), suggesting that the axons were among those which had been affected by the lesion. This early study examined the central demyelinating lesion induced by the injection of diphtheria toxin into the cat dorsal columns, ${ }^{7.40}$ but, as noted above, this lesion contained several types of demyelination. including segmental demyelination, paranodal demyelination." partial demyelination (i.e. myelin thinning $)^{\text {s.9 }}$ and, starting at 19 days. axons repaired by remyelination. ${ }^{x}$ The demyclinated portions of the axons were either completely naked, or partially or completely ensheathed by astrocytic or Schwann cell processes. ${ }^{7}$ Because the lesion contained a range of myelin abnormalities. it was not possible to determine whether conduction would occur in the segmentally demyelinated axons which are probably of most relevance to central demyelinating diseases such as MS and optic neuritis. The more recent studies of conduction in central demyelinated axons have used more homogeneous lesions, but have still not been able to determine the presence or absence of conduction in segmentally demyelinated axons. ${ }^{10} 13.35$

This problem has, however. recently been overcome through studies in which the conduction properties of individual demyelinated central axons have been established, and then the axons labelled with horseradish peroxidase so that they could subsequently be identified beneath the light and electron microscope (P. A. Felts and K. J. Smith. unpublished observations). These studies have established that segmentally demyelinated axons can conduct, and that they have the properties expected of such axons. as described below. The studies have also raised the possibility that the patchy or continuous ensheathment of demyelinated axons by glial processes, even without remyelination, can promote the restoration of conduction, although we have found that continuous ensheathment is not an absolute requirement for conduction. The presence of conduction in at least some demyelinated axons which remain unensheathed for portions of their length is of particular interest with regard to earlier immunocytochemical observations showing that it is only glial-ensheathed demyelinated central axons which exhibit high densities of axolemmal sodium channels, ${ }^{35}$ and to other studies showing that node-like axonal specialisations can form along demyelinated central axons, but only at sites where the axons are contacted by glial processes. ${ }^{35} 38$

However, although some unensheathed demyelinated axons can conduct, it is too soon to conclude that unensheathed demyelinated axolemma can be excitable, since at present the longitudinal extent over which demyelinated axons can be unensheathed, and yet still conduct, remains unknown. If the length is relatively short (e.g. $100 \mu \mathrm{m}$ ), then it may be that conduction could continue in a 'microsaltatory' manner even if the unensheathed axolemma were inexcitable, as appears to be the case in some demyelinated axons in peripheral nerve. ${ }^{33,41}$ The presence of conduction in at least some continuously or patchily ensheathed demyelinated axons, and even in axons completely unensheathed for short (e.g. $100 \mu \mathrm{m}$ ) distances, is of interest with regard to a detailed ultrastructural study which has shown the presence of these different types of demyelinated axon in MS lesions: ${ }^{42}$ the fact that conduction can occur in each type of axon can explain the several reports of clinically 'silent' demyelinating lesions in pathways where conduction block would be expected to cause symptoms. ${ }^{2 .+3.44}$ The restoration of conduction to demyelinated axons is likely to be an important cause of the remissions often seen in central demyelinating diseases (see also Conduction in Remyelinated Central Axons below).

Since a major cause of the symptoms in diseases such as MS and optic neuritis is conduction block in central demyelinated axons, it follows that pharmacological agents which can restore conduction may be effective in the symptomatic therapy of such diseases. Potential strategies for the use of such agents have been discussed ${ }^{45-51}$ (and Blakemore, this issue ${ }^{5 / a}$ ) and in clinical trials some agents have been demonstrated to be effective in reducing symptoms ${ }^{17.52-5+}$ (see also discussion under Effects of Temperature and Transmission of Impulse Trains below).

\section{CONDUCTION SI,OWING}

It is clear that when conduction occurs in central demyelinated axons it is with a slow velocity, and so the latency of conduction is prolonged (Fig. IE). The slowing of conduction is restricted to the demyelinated portion of the fibre. ${ }^{17}$ The conduction velocity specifically along the demyelinated segment has not been determined in central demyelinated axons as precisely as in their peripheral counterparts, but the velocity is likely to be no more than 1-3 m/s (P. A. Felts and K. J. Smith, unpublished observations).

Conduction slowing can account for certain subtle signs and symptoms in central demyelinating diseases, such as the Pulfrich phenomenon noticed by some patients with unilateral optic neuritis ${ }^{55}$ (one patient with optic neuritis reported that oncoming traffic appeared to travel in a curve towards him; personal communication), and it may also interfere with vibration sensation, which depends upon the arrival in the brain of synchronised bursts of activity along different axons. ${ }^{3.56} \mathrm{~A}$ generalised, similar delay in latency across many axons probably does not impair function significantly, since such delays must occur upon cooling of the limbs on a cold day and yet casual observation indicates that satisfactory function is preserved. MS patients also often fail to perceive any deficit in vision even when there are gross delays in the visual evoked potential. ${ }^{57}$ 


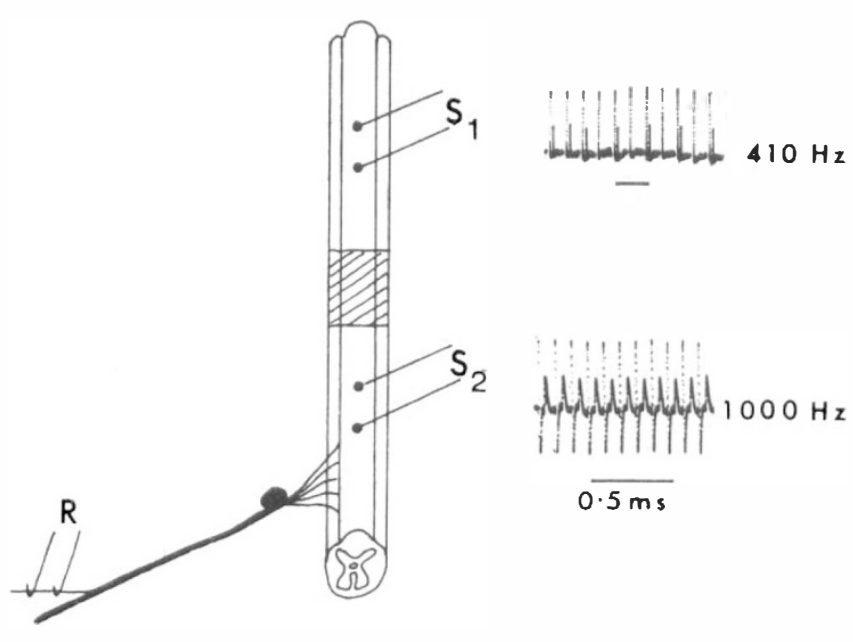

Fig. 3. Records of activity in a single unit isolated from an intercostal nerve caudal to an experimental demyelinating lesion (hatched area) in the cat dorsal column. The lower record shows that when the conduction pathwayexcluded the lesion the unit was able faithfully to follow supramaximal stimuli applied at $1000 \mathrm{~Hz}$, but when the lesion was included in the conduction pathway (upper record) the unit was only able to follow stimuli at $410 \mathrm{~Hz}$ : indeed, after the first few responses the unit was able to conduct only the impulses arising from alternate stimuli. In this figure the action potentials are the shorter, continuous lines immediately following each stimulus artefact, which appears as a dotted line. (Reprinted from McDonald and Sears ${ }^{17}$ with permission).

\section{EVOKED POTENTIALS}

Slowed conduction in demyelinated central axons, possibly coupled with a reduction in the total number of axons conducting, leads to significant delays and other alterations in the visual, somatosensory and brainstem auditory evoked potentials. ${ }^{4.57-66}$ The changes in the form of the evoked potential, particularly the increase in latency, have proved to be of significant value in the diagnosis of demyelinating disorders such as multiple sclerosis. ${ }^{4,67,68}$ McDonald ${ }^{69}$ has estimated that the reduced conduction velocity associated with demyelination provides a sufficient cause of the prominent delays in visual evoked potentials, and this view is supported by the observation that in MS the delay in the visual evoked potential persists after the recovery of vision, in combination with persistent demyelination of the optic nerve. ${ }^{57}$

\section{REFRACTORY PERIOD OF TRANSMISSION}

Recordings from single fibres passing through central demyelinating lesions have shown that some axons, presumed demyelinated, are less able than others to conduct closely spaced pairs of impulses (Fig. 1D). ${ }^{17}$ McDonald and Sears introduced the term 'the refractory period of transmission (RPT)' to describe this property, and the RPT is defined as the maximum interval between two supramaximal stimuli at which the action potential arising from the second stimulus just fails to be propagated through the lesion. Thus the RPT is distinct from the more commonly described 'refractory period', which measures properties of the axon at the stimulating cathode. ${ }^{70}$ In demyelinated axons the RPT is prolonged partly as a consequence of the slowed conduction through the lesion: the reduced conduction velocity means that the first impulse lingers at the demyelinated site, preventing transmission of a second impulse following closely behind. McDonald and Sears ${ }^{17}$ found the normal range of RPT in the cat dorsal columns to be $0.4-1.1 \mathrm{~ms}$ (mean $0.86 \mathrm{~ms}$ ), but this was prolonged to $1.2-4.2 \mathrm{~ms}$ in most axons passing through the site of a demyelinating lesion. More recent studies have confirmed that the RPT is prolonged in axons proven upon ultrastructural examination to be segmentally demyelinated, with the RPT ranging from 0.55 to $1.4 \mathrm{~ms}$ (mean $0.83 \mathrm{~ms}$, $n=21$ ) along the unaffected part of the central axons, to $1.0-27.0 \mathrm{~ms}$ (mean $3.76 \mathrm{~ms}$ ) in the same axons when the lesion was included in the conduction pathway (P. A. Felts and K. J. Smith, unpublished observations). The factors underlying the increase in RPT have recently been studied using computer simulations of conduction along partially demyelinated axons. ${ }^{71}$

\section{TRANSMISSION OF IMPULSE TRAINS}

The prolonged RPT of demyelinated axons inevitably limits the maximum frequency at which the axons can transmit trains of impulses (Fig. 1F, G), but this deficit is only one of three deficits expressed by demyelinated axons with respect to the conduction of impulse trains. Demyelinated axons can also accumulate refractoriness with continued activation such that the maximum frequency which can be transmitted is progressively reduced (Fig. 1H) ${ }^{17.72}$ For example, an axon may be able to conduct two or three impulses at $410 \mathrm{~Hz}$, but then only to conduct impulses in response to alternate stimuli (Fig. 3). ${ }^{17}$ In other axons McDonald and Sears found conduction deficits revealed only at $70 \mathrm{~Hz},{ }^{73}$ a frequency well within the range at which axons are normally required to fire. The accumulation of refractoriness may well contribute to the increasing weakness and fatigue observed upon sustained muscular contraction in MS patients, 'and possibly to the 'fading out' of vision reported by some MS patients if the gaze is fixated on a point for several seconds. ${ }^{74}$

The third deficit expressed by demyelinated central axons during the conduction of impulse trains is the appearance of intermittent periods of complete conduction block (Fig. 1I). These periods develop after sev-

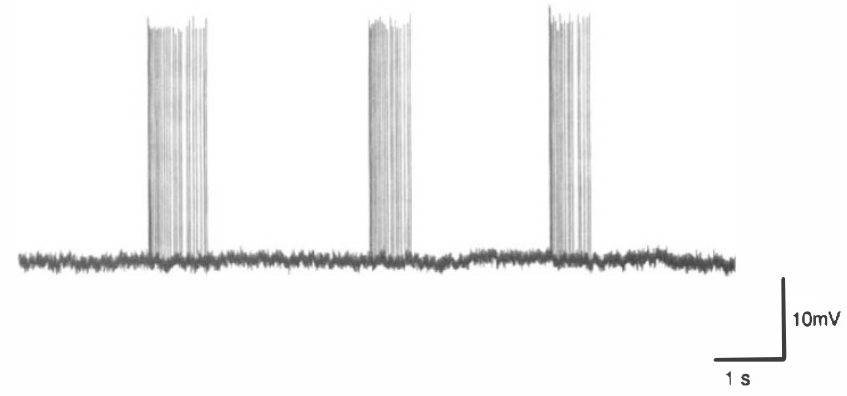

Fig. 4. Record showing bursts of ascending impulses recorded from a sensory axon in the rat dorsal column, a few millimetres rostral to a central demyelinating lesion. The impulses arose at the site of demyelination in the absence of any deliberate stimulation. (R. Kapoor, P. A. Felts and K. J. Smith, unpublished observations). 


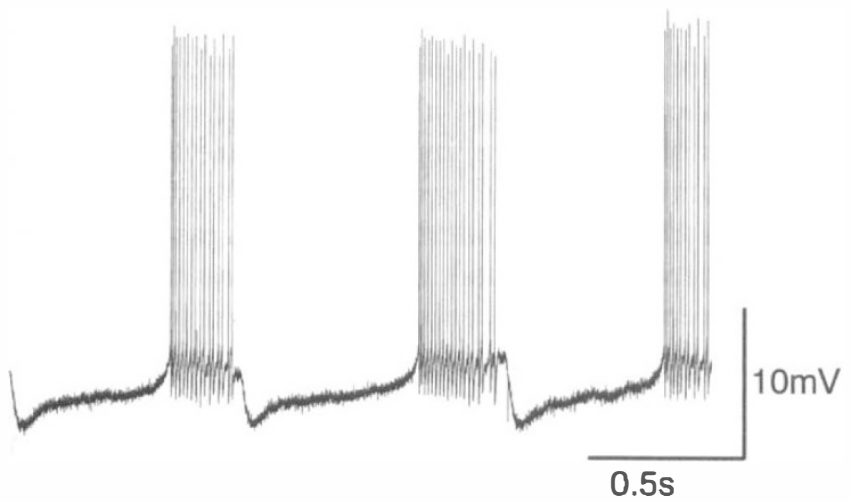

Fig. 5. Bursts of ectopic impulses recorded intra-axonally from a sensory axon in a rat dorsal column containing an experimental demyelinating lesion. In cont rast to the record in Fig. 4 , the recording micropipette is situated within the demyelinating lesion and the changes in membrane potential which generate the bursts are clearly seen. The bursts result from a platean of depolarisation which is terminated by a period of hyperpolarisation believed to arise from activity of the $\mathrm{Na}^{+} / \mathrm{K}^{+}$-ATPase, or sodium pump. (R. Kapoor, P. A. Felts and K. J. Smith, unpublished observations.)

eral seconds of stimulation at relatively high frequency (e.g. $200 \mathrm{~Hz}$ ), and divide the impulse train into bursts of impulses separated by silent intervals of approximately 0.5-2 s (Fig. 4; R. Kapoor, P. A. Felts and K. J. Smith, unpublished observations). In peripheral demyelinated axons the periods of conduction block have been shown to be due to membrane hyperpolarisation resulting from activity of the $\mathrm{Na}^{+} / \mathrm{K}^{+}$ATPase, ${ }^{75.76}$ and this finding has now also been extended to central demyelinated axons (Fig. 5; R. Kapoor, P. A. Felts and K. J. Smith, unpublished observations). During the period of $200 \mathrm{~Hz}$ stimulation it is supposed that a sufficient accumulation of potassium ions occurs outside the axon, and of sodium ions inside, that the activity of the $\mathrm{Na}^{+} / \mathrm{K}^{+}$-ATPase is stimulated: this pump is electrogenic, contributing to membrane hyperpolarisation. Bostock and Grafe ${ }^{76}$ have also discussed other mechanisms which may contribute to deficits in the transmission of high-frequency impulse trains, including the accumulation of sodium ions within the axon at the driving node, ${ }^{77}$ and depolarisation of the demyelinated axons due to increases in extracellular potassium. ${ }^{78}$

If the intermittent conduction block is due to activity of the $\mathrm{Na}^{+} / \mathrm{K}^{+}$-ATPase, it may be predicted that inhibitors of this pump, such as ouabain, may temporarily alleviate the conduction block. However, we have found this prediction difficult to prove in vitro, perhaps due to the relative inaccessibility of the central lesion to this particular drug (R. Kapoor, P. A. Felts and K. J. Smith, unpublished observations). However, such drugs have been reported to improve conduction in peripheral ${ }^{79}$ and central ${ }^{80}$ demyelinated axons, and to improve symptoms in three of seven patients with probable or definite MS. ${ }^{+7}$

The reduced ability of central demyelinated axons to conduct trains of impulses may contribute to the reduced flicker fusion frequency observed in patients, ${ }^{81}$ and which is also apparent when monitoring the visual evoked potential: ${ }^{82,83}$ similar changes occur in the somatosensory evoked potential. ${ }^{84}$

\section{EFFECTS OF TEMPERATURE}

It is well known to many MS patients that changes in body temperature can affect symptoms, and as early as 1890 Uhthoff, an ophthalmologist, described deterioration of vision upon exercise. ${ }^{85}$ Indeed, the effects of temperature changes on the symptoms and signs of MS are well documented (Fig. 1 J, K $)^{86-93}$ and there have been several accounts of the extreme sensitivity of symptoms to changes in body temperature (reviewed by Matthews ${ }^{94}$ ) such as improvements in vision upon drinking a glass of cold water, ${ }^{95}$ or the deleterious effects of sunbathing, ${ }^{96}$ a hot shower, ${ }^{97}$ hot drink, or the use of a hair dryer, ${ }^{98}$ changes due to circadian temperature variations have also been reported. ${ }^{99,100}$ Indeed, the deterioration in symptoms can be so rapid and severe upon warming that a patient may require support to prevent drowning in a hot bath, ${ }^{101}$ and, indeed, a fatal case of scalding in a hot bath has been reported. ${ }^{97}$ The effects of warming are relatively specific to central demyelinating diseases, and diagnostic use has been made of the phenomenon, the 'hot bath test'. ${ }^{\text {102-104 }}$ The temperature-induced changes in symptoms are typically reversible (but see also Berger and Sheremata ${ }^{96,105}$ and Davis ${ }^{106}$ ).

The effects of temperature on the symptomatology of MS predict that temperature increases will contribute to conduction block in central demyelinated axons, and vice versa, and this view is supported by computer simulations ${ }^{18,46}$ and experimental observations in peripheral demyelinated axons. ${ }^{49.50 .107-110}$ The effects of temperature on central demyelinated axons have now been examined directly, using the demyelinating lesion induced by the intraspinal injection of ethidium bromide (Fig. 6) (P. A. Felts and K. J. Smith, unpublished observations). Notably,

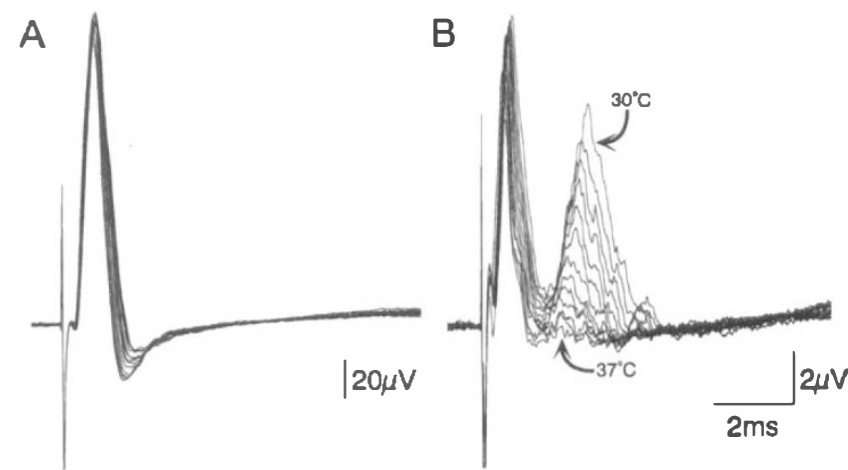

Fig. 6. Two series of superimposed, monophasic compound action potentials recorded in vitro from a normal rat dorsal column $(A)$ and one containing an experimental demyelinating lesion $(B)$. The delayed peak in $(B)$ is due to conduction in segmentally demyelinated axons. The stimulating and recording conditions remained constant throughout the experiment, but the different records were obtained as the central length of the column (which contained the demyelinated lesion in B) was progressively warmed from $30^{\circ} \mathrm{C}$ to normal body temperature $\left(37^{\circ} \mathrm{C}\right)$. Note that the temperature changes had little effect on conduction in the normal axons in $(A)$ and $(B)$, but that many more demyelinated axons were able to conduct at the cooler temperatures: virt ually no demyel inated axons were able to conduct through the lesion at body temperature. (P. A. Felts and $K$. J. Smith, unpublished observations). 
virtually no demyelinated axons are able to conduct at normal body temperature, despite the presence in the preparation of many axons capable of conducting when cooled. This type of observation has encouraged a search for pharmacological agents which may mimic the effects of temperature in the hope that such agents may provide an effective symptomatic therapy for central demyelinating diseases (reviewed by Davis and Schauf ${ }^{48}$ and Sears et $\left.a l{ }^{49}\right)$. Attention has focussed on the potassium channel blocking agents, notably 4-aminopyridine (4-AP) ${ }^{111} 115$ (see also Bostock et al.$^{45}$ ), and this agent has been shown to reduce symptoms in MS patients in clinical trials. ${ }^{53,54,93,116-120}$ The effects of 4-AP on conduction in experimentally demyelinated central axons have now been investigated in vitro (P. A. Felts and K. J. Smith, in preparation).

Temperature exerts its effects mainly by altering action potential duration. ${ }^{70,121}$ For example, temperature increases shorten action potential duration, largely due to the temperature coefficient for sodium inactivation being larger than that for sodium activation. ${ }^{46.18}$ The relative brevity of the action potential at increased temperatures allows less time for local currents to depolarise the demyelinated axolemma to its firing threshold, and, in cases where the safety factor for conduction is only fractionally greater than unity, conduction block is likely to occur. Variations in the extracellular calcium ion concentration can also modulate symptoms in MS. ${ }^{\text {?? }}$

\section{ECTOPIC ACTIVITY}

The presence of ectopic discharges is well documented in peripheral demyelinated, ${ }^{123-125}$ chronically injured ${ }^{126}$ and amyelinated $^{127-129}$ axons, but studies in central demyelinated axons are few.

Smith and McDonald ${ }^{130.131}$ reported the presence of ongoing discharges in axons passing through a demyelinating lesion caused by the intraspinal injection of lysophosphatidyl choline, and showed that the discharges arose ectopically at the lesion, propagating in both directions from it. The discharges were either of evenly spaced impulses, or of bursts of impulses (Fig. 1L), and they continued for long periods (hours) in the absence of any deliberate stimulation. These authors argued that since the discharges occurred for prolonged periods across many sensory axons, the discharges provided a sufficient explanation for many of the 'positive' symptoms commonly experienced by patients with central demyelinating disorders, such as tingling paraesthesiae.

The demyelinated axons were also extremely mechanosensitive (Fig. 1M), such that the firing rate of discharging units was markedly increased upon even small deformations of the lesion using an eyelash, and such mechanical stimulation also induced activity in many axons which were otherwise electrically silent. This mechanosensitivity of the axons has been advanced as an explanation for the phenomenon of Lhermitte's symptom, ${ }^{132,133}$ namely a radiating pins and needles sensation upon stretching the cervical spinal cord, for example upon bending to tie a shoe lace: the cervical cord is a common location for lesions in MS patients.

Mechanosensitivity can also explain the perception of phosphenes observed upon eye movement by some patients with demyelinating lesions in the optic nerves. ${ }^{134}$

The mechanism(s) underlying the ectopic discharges are not clearly understood. Ephaptic interactions (crosstalk) between axons may account for some discharges, but although such interactions have been shown between normal and amyelinated peripheral axons in the dystrophic mouse. ${ }^{123.129 .135}$ they have yet to be shown between demyelinated axons within the CNS. Recent observations suggest that spontaneous activity can, however, arise in central demyelinated axons from inward, and thereby excitatory, potassium currents consequent upon a locally raised external potassium ion concentration ${ }^{136.137}$ (see also Young et $\left.a_{l} .^{138}\right)$. Thus previously silent demyelinated central axons can be induced to express ongoing bursts of discharges (not shown), and bursts of impulses initiated by single action potentials (Figs. 1N, 7), by procedures expected to raise the extracellular potassium concentration.

Potential mechanism(s) underlying the paroxysmal symptoms of $\mathrm{MS}^{9+4}$ have been discussed by Rasminsky ${ }^{125}$ and may involve the ephaptic excitation of myelinated axons which happen to be located adjacent to demyelinated axons. It is also possible that if adjacent demyelinated axons are not separated by intervening glial processes they may be able to excite each other, resulting

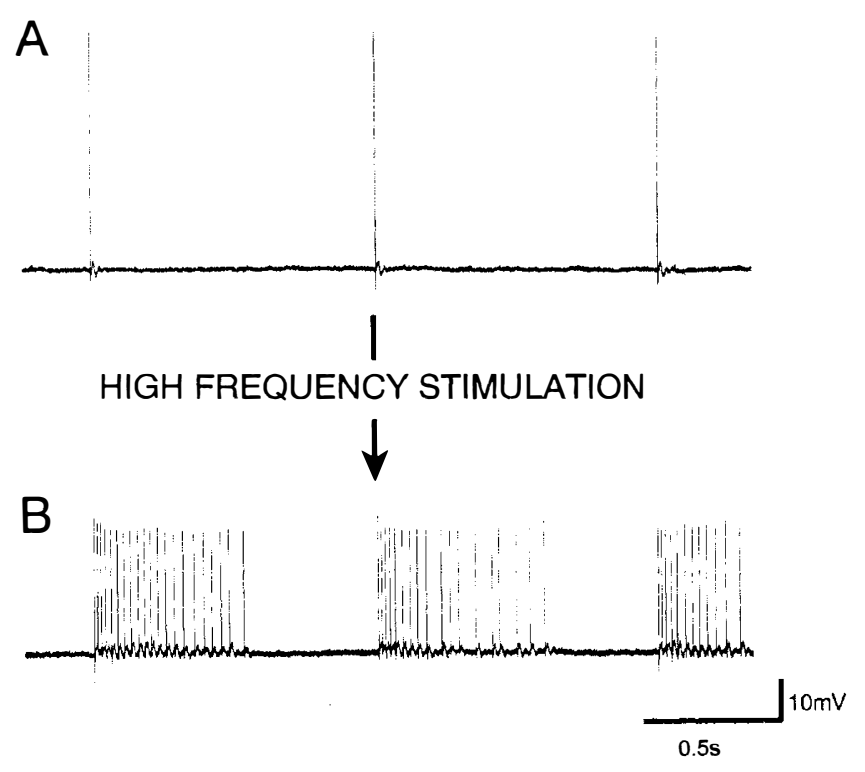

Fig. 7. Records obtained intra-axonally from a demyelinated sensory axon in the rat dorsal column, at or near the site of the lesion. Single electric stimuli at $1 \mathrm{~Hz}$ (arrows) presented to the dorsal column on the opposite side of the lesion normally resulted in single impulses which traversed the lesion to the recording electrode. However: after several seconds of highfrequency stimulation (200 $H_{-}$, not shown) the single impulses (arrowsi evoked short bursts of additional. ectopic impulses as they traversed the site of the lesion. (R. Kapoor, P. A. Felts and K. J. Smith, unpublished observations.) The high-frequency stimulation is expected to raise the extracellular potassium ion concentration. 
in a synchronous, lateral spread of excitation across many axons, ${ }^{139}$ although this remains unproven.

\section{TOXIC OR 'NEUROELECTRIC BLOCKING' FACTORS}

A research area of great potential importance to MS concerns the putative existence of circulating factors which can modulate symptoms in the disease. The evidence in favour of such factors is unfortunately conflicting and inconclusive, but it seems appropriate to include this research area in this review which attempts, in part, to illuminate the genesis of symptoms in MS.

The research is founded in the belief by some investigators that the production of symptoms in MS cannot be completely explained by demyelination. ${ }^{1+1.1+1}$ (see also Rose $^{142}$ ). This view was encouraged by the observation that relapses and remissions can occur quite rapidly in the disease, perhaps too rapidly to be readily explained by demyelination and remyclination alone: ${ }^{1+3}$ indeed, at the time, remyelination was thought to be very limited or absent in this disease. The suspicion that MS symptoms were not necessarily due to demyelination was strengthened by several reports which described the presence of prominent symptoms in animals with EAE, although little or no demyelination was detected to account for them. ${ }^{14-151}$ These findings indicated that unknown factor(s) were contributing to the symptoms of MS and EAE by blocking conduction: these factors were called neuroelectric blocking factors.

As time has progressed, however, the rationale predicting the presence of neuroelectric blocking factors has been largely undermined, for we now know that demyelination can occur quite rapidly in both central and peripheral nervous systems, ${ }^{10.11 .152}$ and careful histological study of animals with EAE has revealed ample demyelination to account for the deficits observed. ${ }^{153-15 h}$ Furthermore, it is now clear that remyelination can be quite complete in both the early MS lesion, ${ }^{157.158}$ and in EAE, ${ }^{154}$ and where it occurs it presumably contributes to remissions. ${ }^{6}$ However, although the reasons for predicting the presence of neuroelectric blocking factors may have diminished, there are several reports that such factors are present in demyelinating disorders.

The first, relatively small study indicating the possible presence of such factors indicated that, within minutes of application, sera obtained from animals with EAE and from MS patients during acute exacerbation partially blocked reflex activity evoked in cultured mouse brain and spinal cord. ${ }^{159}$ The blocking activity was described as reversible and dependent upon complement, although few controls were examined. The findings were supported $^{1+1.160 .161}$ by similar studies examining isolated frog spinal cord, which, in addition, indicated that the blocking activity was specific to MS sera and was not found in either normal human sera or in sera from patients with several other neurological disorders. These findings were confirmed by Lumsden et al. ${ }^{162.16 .3}$ using guinea pig tissue and again by Schauf et al. ${ }^{164}$ using an isolated frog spinal cord preparation. The blocking activity was later found to be correlated with the occurrence of clinical signs and symptoms in MS. ${ }^{165.166}$

However. Seil's group, examining reflex activity evoked in mouse cerebral neocortex, found neuroelectric blocking activity not only in sera from patients with $\mathrm{MS}^{167}$ and from rats with $\mathrm{EAE}^{168}$ (irrespective of the clinical state $)^{169}$ but also in sera from control rats and from normal human volunteers. Blocking activity was also found in normal rat and human sera by another group. ${ }^{170}$ Seil et al. therefore concluded that the neuroelectric blocking activity was a non-specific property of many human and animal sera, although these authors pointed out that the blocking activity may still act relatively specifically since it is only when the blood-brain barrier is compromised (as it is in MS) that serum factors may be expected to gain access to the CNS. ${ }^{167}$

It should be noted that further studies by other groups failed to detect blocking activity in normal sera, or sera from patients suffering from Guillain-Barré syndrome (unpublished observations cited in Schauf and Davis ${ }^{1+3}$ ) or strokes $^{165}$ (but see Schmutz et al. ${ }^{171}$ ), although blocking activity was found in sera from patients with amyotrophic lateral sclerosis ${ }^{172}$ and certain other diseases. ${ }^{171}$ The reasons for the conflicting findings remain unexplained, but have been attributed partly to differences in the recording techniques and in the interpretation of the data, and to differences in the type of explant examined. ${ }^{173.174}$

The identity of the blocking factor(s) remains uncertain, although most studies report a suspected role for antineural antibodies, due partly to the apparent dependence of the blocking activity on complement, and partly to the localisation of the blocking activity in the IgG-containing fraction of serum. ${ }^{1+3.166 .170}$ Furthermore, plasma exchange in MS patients, which removes factors such as bloodborne antibodies and immune complexes, also reduces or eliminates serum neuroelectric blocking activity. ${ }^{1+3.175}$ If antibodies are involved, then it is likely that they act by means other than demyelination ${ }^{176.177}$ since their action is both rapid (within minutes) and reversible. It seems likely that factors other than antibodies are also involved, since Seil's studies indicated the presence of several serum neuroelectric blocking factors, not all of which were antibodies and only some of which were complement dependent. $^{167}$

With more recent knowledge it seems possible that some of the blocking activity may have been due to factors associated with inflammation, ${ }^{66.178}$ since several cytokines have now been reported to affect ionic currents in neural tissues. ${ }^{174}{ }^{186}$ Whether cytokines are involved in the modulation of either synaptic transmission or of conduction in demyelinated axons remains uncertain, although it is an interesting possibility which forms an exciting and potentially rewarding area for current and future research.

Notwithstanding the above, the relationship between neuroelectric blocking factors and the symptomatology of demyelinating disease remains obscure, as does the potential mechanism of their action in the disease. It is note- 
worthy that neuroelectric blocking activity is assayed by detecting the ability of sera to depress the amplitude of reflex activity evoked by the electrical stimulation of CNS tissue. Thus the sera are assayed mainly for their actions on synaptic transmission, and not for their action on demyelinated axons. This distinction is important but easily overlooked since the relevant literature is concerned with the role of blocking factors in the symptomatology of demyelinating disease, and some authors suggest that the factors might be expected to cause conduction block in demyelinated axons due to their low safety factor for conduction. ${ }^{165,166}$ In fact, when sera with potent neuroelectric blocking activity were eventually tested for their effect on myelinated and demyelinated axons, no detectable effect was found. ${ }^{143}$ The sera did. however, inhibit transmitter release at the frog neuromuscular junction, ${ }^{143}$ consistent with the blocking effect detected on reflex activity in the CNS.

Therefore, if neuroelectric blocking factors do affect symptoms in MS, it is likely that they do so by depressing synaptic transmission, rather than by promoting conduction block in demyelinated axons. However. whether the factors have any role in the symptomatology of MS is uncertain, since cerebrospinal fluid was found to be generally free of blocking activity, even in those patients in whom corresponding serum samples had potent neuroelectric blocking activity. ${ }^{1+3}$ In summary. while it seems likely that factors other than demyelination may affect symptoms in MS, especially given the low safety factor for conduction in many demyelinated axons, the role of serum 'neuroelectric blocking factors' remains unclear.

\section{CONDUCTION IN REMYELINATED CENTRAL AXONS}

There are two reasons for suspecting that the repair of demyelination by remyelination may not necessarily be accompanied by the restoration of conduction to the repaired axons. First, remyelinated internodes are shorter than the normal internodes they replace, ${ }^{187.188}$ and so the new nodes of Ranvier are formed around axolemma which was previously covered by myelin and which therefore lacks the high concentration of sodium channels normally present at the node. ${ }^{19}$ Second, remyelinated internodes are noticeably thinner than normal, ${ }^{187.188}$ which may be expected to increase membrane capacitance and thereby reduce the safety factor (although computer simulations suggest that even a very thin myelin sheath may be compatible with conduction). ${ }^{18.189}$

The diphtheria toxin lesion, which revealed many of the fundamental conduction properties of central demyelinated axons, does not undergo extensive remyelination ${ }^{7}$ and determination of the conduction properties of central remyelinated axons awaited development of the central LPC lesion. ${ }^{190}$ In this lesion all the demyelinated axons are eventually repaired by remyelination, effected largely by oligodendrocytes although some axons are repaired by Schwann cells which invade the central nervous system. Serial electrophysiological study of the lesion established that remyelination was accompanied by the restoration of conduction to most, if not all, of the remyelinated axons, ${ }^{(1) .11}$ and that the repaired axons conducted securely, with refractory periods of transmission indistinguishable from normal: the conduction velocity was also improved such that the latency of the response was returned to within normal limits. A later, similar, study established that the repair of central axons by Schwann cells (the peripheral myelinating cell) was similarly effective in restoring secure conduction, ${ }^{12}$ raising the possibility that the transplantation of Schwann cells to central lesions may be effective in reversing symptoms. Such an approach would result in the formation on the central axons of peripheral myelin which. by analogy with the sparing of myelin in the peripheral nervous system in MS. may be resistant to the disease process.

Remyelination is believed to contribute to recovery from acute EAE ${ }^{155}$ and since it is now known that remyelination can be quite widespread in some lesions in MS, ${ }^{157.191 .192}$ it is probable that remyelination contributes to the remissions commonly seen in this disease. ${ }^{6}$

\section{SOME AVENUES FOR THE SYMPTOMATIC THERAPY OF CENTRAL DEMYELINATING DISEASE}

It is now proven that central demyelinated axons can conduct, but it is also clear that frequently they fail to conduct in central demyelinating diseases. Since the fundamental wiring of the CNS is largely preserved in such diseases, it is reasonable to believe that an effective symptomatic therapy may be built around the reversal of this persistent conduction block. Certainly this belief is encouraged by the common observation that symptoms can be substantially improved by the restoration of conduction resulting from a reduction in body temperature (see above). Therefore, one promising avenue for research concerns the identification of safe drugs which mimic temperature reductions in that they restore conduction by prolonging action potential duration. A problem with some of the agents examined so far (e.g. scorpion toxin, 4-AP) is the possibility of convulsant side effects resulting from the increased quantities of transmitter released at central synapses in response to the prolonged action potentials. However, it is conceivable that agents may be found which bind to channels (yet to be identified) which are specific to regions of demyelinated central axolemma, and such agents could be relatively free from dangerous side effects. Certainly, the realisation that there are a multiplicity of channels and receptors (particularly potassium channels but including ATPases, ion exchangers and receptors for neurotransmitters) along normal and demyelinated axons gives realistic hope that a pharmacological therapy targeted specifically at demyelinated lesions may be achieved.

As mentioned above, one potassium channel blocking agent, 4-AP, is partially effective in the symptomatic therapy of MS. However, there is also evidence that at the concentrations achievable in patients 4-AP may exert its 
beneficial effects not by the restoration of conduction to blocked axons, as is commonly supposed, but rather by the potentiation of synaptic transmission (P. A. Felts and K. J. Smith, unpublished observations). It is easy to imagine that in a pathway where conduction in many axons is blocked, the potentiation of synaptic transmission in the few remaining axons may result in a partial remission of symptoms. This consideration is exciting in that it raises the possibility of a new avenue for the symptomatic therapy of MS, namely one directed at synaptic transmission. This approach would circumvent the problem of persistent conduction block in demyelinated axons (P. A. Felts and K. J. Smith, in preparation).

The potential role that oedema, inflammation and inflammatory mediators may play in the promotion of conduction block remains uncertain and largely unexplored, but it is likely that research into these areas will be rewarded with new insights for the symptomatic therapy of central demyelinating disease.

With regard to 'positive' symptoms (e.g. paraesthesiae and phosphenes), it is likely that potential avenues for the elimination of ectopic impulses may arise from a better understanding of the mechanism(s) underlying their generation. Recent evidence ${ }^{136.137}$ implicates a role for disordered potassium homeostasis which may be overcome by manipulating the glial environment of the demyelinated axons.

It is known that remyelination is effective in restoring secure conduction to demyelinated axons, ${ }^{10.12}$ but that remyelination is typically limited in extent in MS. Now that it is possible to use MRI safely to identify the locations of demyelinating lesions during life, it may be possible to transplant cultured glial or Schwann cells directly into symptomatic lesions (e.g. in the optic nerve) to effect both a morphological and functional repair (Targett and Blakemore, this issue 51a). Alternatively, it may be possible to administer glial growth and/or trophic factors to promote the natural tendency of central demyelinating lesions to undergo repair by endogenous glial cells. The apparent ability of glial cells to influence the assortment of voltage-sensitive channels along demyelinated axolemma ${ }^{35}$ offers another avenue by which glial transplantation may promote remission from symptoms. Other potential avenues for the therapy of central demyelinating diseases have recently been reviewed. . $^{19.51 .193}$

I wish to thank Dr P. A. Felts, Professor R. A. C. Hughes and Dr R. Kapoor for their helpful comments on the text. The support of the Multiple Sclerosis Society, the Wellcome Trust, the British Council and the Special Trustees of Guy's Hospital is gratefully acknowledged.

Key words: Action potentials, Demyelinating diseases, Electrophysiology, Multiple sclerosis, Neural conduction, Sodium channels.

\section{REFERENCES}

1. McDonald WI, Sears TA. Effect of demyelination on conduction in the central nervous system. Nature 1969;221: 182-3.

2. Ulrich J, Groebke-Lorenz W. The optic nerve in multiple sclerosis: a morphological study with retrospective clinico- pathological correlations. Neuro-ophthalmology 1983;3: 149-59.

3. McDonald WI. Mechanisms of functional loss and recovery in spinal cord damage. Ciba Found Symp 1975:33: $23-33$.

4. Halliday AM, McDonald WI. Pathophysiology of demyelinating disease. Br Med Bull 1977;33:21-7.

5. Waxman SG. Clinical course and electrophysiology of multiple sclerosis. In: Waxman SG, editor. Advances in neurology, vol. 47. Functional recovery in neurological disease. New York: Raven Press, 1988:157-84.

6. McDonald WI. The pathophysiology of multiple sclerosis. In: McDonald W1. Silberberg DH, editors. The diagnosis of multiple sclerosis. London: Butterworth, 1986: 112-33.

7. Harrison BM, McDonald WI, Ochoa J. Central demyelination produced by diphtheria toxin: an electron microscopic study. J Neurol Sci 1972:17:281-91.

8. Harrison BM, McDonald WI, Ochoa J. Remyelination in the central diphtheria toxin lesion. J Neurol Sci 1972:17: 293-302.

9. Harrison BM, McDonald WI. Ochoa J, Ohlrich GD. Paranodal demyelination in the central nervous system. J Neurol Sci 1972:16:489-94.

10. Smith KJ, Blakemore WF. McDonald WI. The restoration of conduction by central remyelination. Brain 1981;104: 383-404.

11. Smith KJ, Blakemore WF. McDonald WI. Central remyelination restores secure conduction. Nature 1979:280: $395-6$.

12. Felts PA, Smith KJ. Conduction properties of central nerve fibres remyelinated by Schwann cells. Brain Res 1992:574: 178-92.

13. Pender MP. The pathophysiology of acute experimental allergic encephalomyelitis induced by whole spinal cord in the Lewis rat. J Neurol Sci 1988;84:209-22.

14. Mayer RF. Conduction velocity in the central nervous system of the cat during experimental demyelination and remyelination. Int J Neurosci 1971;1:287-308.

15. Mayer RF. The effect of demyelination on conduction in cat spinal cord. In: Proceedings of the Second PanAmerican Congress on Neurology 1967:408-19.

16. Mayer RF. Conduction velocity in spinal cord during experimental demyelination in the cat. Trans Am Neurol Assoc 1966;91:294-6.

17. McDonald WI. Sears TA. The effects of experimental demyelination on conduction in the central nervous system. Brain 1970:93:583-98.

18. Koles AJ, Rasminsky M. A computer simulation of conduction in demyelinated nerve fibres. J Physiol (Lond) 1972;227:35I-64.

19. Waxman SG, Ritchie JM. Molecular dissection of the myelinated axon. Ann Neurol 1993;33:121-36.

20. Ritchie JM, Rogart RB. Density of sodium channels in mammalian myelinated nerve fibers and nature of the axonal membrane under the myelin sheath. Proc Natl Acad Sci USA 1977;74:211-5.

21. Shrager P. Sodium channels in single demyelinated mammalian axons. Brain Res 1989;483:149-54.

22. Waxman SG, Black JA, Kocsis JD, Ritchie JM. Low density of sodium channels supports action potential conduction in axons of neonatal rat optic nerve. Proc Nat Acad Sci USA 1989:86:1406-10.

23. Waxman SG. Demyelination in spinal cord injury. J Neurol Sci 1989:91:1-14.

24. Bostock H, Sears TA. The internodal axon membrane: electrical excitability and continuous conduction in segmental demyelination. J Physiol (Lond) 1978;280: $273-301$.

25. Huxley AF, Stampfli R. Evidence for saltatory conduction in peripheral myelinated nerve fibres. J Physiol (Lond) 1949;108:315-39. 
26. Tasaki I, Takeuchi T. Weitere Studien über den Aktionstrom der markhaltigen Nervenfaser und über die elektrosaltatorishe Übertragung des Nervenimpulses. Arch Ges Physiol 1942;245:764-82.

27. Tasaki I. Nervous transmission. Springfield, Illinois: Charles C. Thomas, 1953.

28. Waxman SG, Brill MH. Conduction through demyelinated plaques in multiple sclerosis: computer simulations of facilitation by short internodes. J Neurol Neurosurg Psychiatry 1978;41:408-16.

29. Waxman SG, Foster RE. Ionic channel distribution and heterogeneity of the axon membrane in myelinated fibers. Brain Res 1980;203:205-34.

30. Waxman SG. Prerequisites for conduction in demyelinated fibers. Neurology 1978;28:27-33.

31. Waxman SG. Conduction in myelinated, unmyelinated, and demyelinated fibers. Arch Neurol 1977;34:585-9.

32. Rasminsky M, Kearney RE, Aguayo AJ, Bray GM. Conduction of nervous impulses in spinal roots and peripheral nerves of dystrophic mice. Brain Res 1978;143:71-85.

33. Smith KJ, Bostock H, Hall SM. Saltatory conduction precedes remyelination in axons demyelinated with lysophosphatidyl choline. J Neurol Sci 1982:54:13-31.

34. Blakemore WF. Ethidium bromide induced demyelination in the spinal cord of the cat. Neuropathol Appl Neurobiol 1982;8:365-75.

35. Black JA, Felts P, Smith KJ, Kocsis JD, Waxman SG. Distribution of sodium channels in chronically demyelinated spinal cord axons: immuno-ultrastructural localisation and electrophysiological observations. Brain Res 1991;544: 59-70.

36. Blakemore WF, Smith KJ. Node-like axonal specialisations along demyelinated central nerve fibres: ultrastructural observations. Acta Neuropathol (Berl) 1983;60: 291-6.

37. Rosenbluth J, Blakemore WF. Structural specialisations in cat of chronically demyelinated spinal cord axons as seen in freeze-fracture replicas. Neurosci Lett 1984;48:171-7.

38. Rosenbluth J, Tao-Cheng J-H, Blakemore WF. Dependence of axolemmal differentiation on contact with glial cells in chronically demyelinated lesions of cat spinal cord. Brain Res 1985;358:287-302.

39. McDonald WI, Sears TA. The effects of demyelination on conduction in the central nervous system. Trans Am Neurol Assoc 1969;94:168-73.

40. McDonald WI, Sears TA. Focal experimental demyelination in the central nervous system. Brain 1970;93: 575-82.

41. Bostock H, Hall SM, Smith KJ. Demyelinated axons can form 'nodes' prior to remyelination. J Physiol (London) 1980;308:21-3.

42. Barnes D, Munro PM, Youl BD, Prineas JW, McDonald WI. The longstanding MS lesion: a quantitative MRI and electron microscopic study. Brain 1991;114:1271-80.

43. Wisniewski HM, Oppenheimer D, McDonald WI. Relation between myelination and function in MS and EAE. J Neuropathol Exp Neurol 1976;35:327.

44. Ghatak NR, Hirano A, Lijtmaer H, Zimmerman HM. Asymptomatic demyelinated plaque in the spinal cord. Arch Neurol 1974;30:484-6.

45. Bostock H, Sherratt RM, Sears TA. Overcoming conduction failure in demyelinated nerve fibres by prolonging action potentials. Nature 1978;274:385-7.

46. Schauf CL, Davis FA. Impulse conduction in multiple sclerosis: a theoretical basis for modification by temperature and pharmacological agents. Journal Neurol Neurosurg Psychiatry 1974;37:152-61.

47. Kaji R, Happel L, Sumner AJ. Effect of digitalis on clinical symptoms and conduction variables in patients with multiple sclerosis. Ann Neurol 1990;28:582-4.
48. Davis FA, Schauf CL. Approaches to the development of pharmacological interventions in multiple sclerosis. Adv Neurol 1981:31:505-10.

49. Sears TA, Bostock H. Conduction failure in demyelination: is it inevitable? Adv Neurol 1981;31:357-75.

50. Sears TA, Bostock H, Sheratt M. The pathophysiology of demyelination and its implications for the symptomatic treatment of multiple sclerosis. Neurology 1978;28:21-6.

51. Kocsis JD, Black JA, Waxman SG. Pharmacological modification of axon membrane molecules and cell transplantation as approaches to the restoration of conduction in demyelinated axons. Res Publ Assoc Res Nervous Mental Dis 1993;71:265-92.

51a. Targett MP, Blakemore WF. The use of xenografting to evaluate the remyelinating potential of glial cell cultures. Eye 1994;8:238-44.

52. Gilmore RL, Kasarskis EJ, McAllister RG. Verapamilinduced changes in central conduction in patients with multiple sclerosis. J Neurol Neurosurg Psychiatry 1985; 48:1140-6.

53. van Diemen HA, Polman $\mathrm{CH}$, van Dongen TM, van Loenen AC, Nauta JJ, van Walbeek HK, Koetsier JC. The effect of 4-Aminopyridine on clinical signs in multiple sclerosis: a randomised, placebo-controlled, double-blind, cross-over study. Ann Neurol 1992;32:123-30.

54. Stefoski D, Davis FA, Fitzsimmons WE, Luskin SS, Rush J, Parkhurst GW. 4-aminopyridine in multiple sclerosis: prolonged administration. Neurology 1991;41:1344-8.

55. Rushton D. Use of the Pulfrich pendulum for detecting abnormal delay in the visual pathway in multiple sclerosis. Brain 1975;98:283-96.

56. Gilliatt RW, Willison RG. Peripheral nerve conduction in diabetic neuropathy. J Neurol Neurosurg Psychiatry 1962; 25:11-8.

57. Halliday AM, McDonald WI. Mushin J. Visual evoked response in diagnosis of multiple sclerosis. BMJ 1973;4: 661-4.

58. McDonald WI, Halliday AM. Diagnosis and classification of multiple sclerosis. Br Med Bull 1977;33:4-9.

59. Onofrj M, Bazzano S, Malatesta G, Gambi D. Pathophysiology of delayed evoked potentials in multiple sclerosis. Funct Neurol 1990;5:301-19.

60. Chiappa KH. Use of evoked potentials for diagnosis of multiple sclerosis. Neurol Clin 1988;6:861-80.

61. Hume AL, Waxman SG. Evoked potentials in suspected multiple sclerosis: diagnostic value and prediction of clinical course. J Neurol Sci 1988;83:191-210.

62. Small DG, Matthews WB, Small M. The cervical somatosensory evoked potential (SEP) in the diagnosis of multiple sclerosis. J Neurol Sci 1978;35:211-24.

63. Matthews WB, Small DG. Serial recording of visual and somatosensory evoked potentials in multiple sclerosis. $\mathrm{J}$ Neurol Sci 1979;40:11-21.

64. Hallpike J. Multiple sclerosis: making the diagnosis. Aust Fam Physician 1992;21:1407-10.

65. Swanson JW. Multiple sclerosis: update in diagnosis and review of prognostic factors. Mayo Clin Proc 1989;64: 577-86.

66. Youl BD, Turano G, Miller DH, Towell AD, Macmanus DG, Moore SG, et al. The pathophysiology of acute optic neuritis. An association of gadolinium leakage with clinical and electrophysiological deficits. Brain 1991;114: 2437-50.

67. Regan D, Murray TJ, Silver R. Effect of body temperature on visual evoked potential delay and visual perception in multiple sclerosis. J Neurol Neurosurg Psychiatry 1977: 40:1083-91.

68. Halliday AM, McDonald WI, Mushin J. Delayed visual evoked response in optic neuritis. Lancet 1972;1:982-5.

69. McDonald WI. Pathophysiology of conduction in central 
nerve fibres. In: Desmedt JE, editor. New developments in visual evoked potentials in the human brain. Oxford: Oxford University Press. 1974:1-19.

70. Paintal AS. The influence of diameter of medullated nerve fibres of cats on the rising and falling phases of the spike and its recovery. J Physiol (Lond) 1966;184:791-811

71. Quandt FN, Davis FA. Action potential ref ractory period in axonal demyelination: a computer simulation. Biol Cybern 1992:67:545-52.

72. Kaji R, Suzumura A, Sumner AJ. Physiological consequences of antiserum-mediated experimental demyelination in CNS. Brain 1988:111:675-94.

73. McDonald WI. The pathophysiology of central nerve fibres. In: Studies in neurophysiology. Cambridge: Cambridge University Press. 1978:363-79.

74. Waxman SG. Clinicopathological correlations in multiple sclerosis and related diseases. Adv Neurol 1981:31: 169--82.

75. Bostock H. Grafe P. Demyelinated rat spinal root fibres fail to transmit long-lasting trains of impulses because of hyperpolarisation. J Physiol (Lond) 1984:357:27P.

76. Bostock H, Grafe P. Activity-dependent excitability changes in normal and demyelinated rat spinal root axons. J Physiol (Lond) 1985;365:239-57.

77. Rasminsky M. Sears TA. Internodal conduction in undissected demyelinated nerve fibres. J Physiol (Lond) 1972; 227:323-50

78. Brismar T. Specific permeability properties of demyelinated rat nerve fibres. Acta Physiol Scand 1981:113: 167-76.

79. Kaji R, Sumner AJ. Ouabain reverses conduction disturbances in single demyelinated nerve fibres. Neurology 1989; 39:1364-8

80. Kaji R, Sumner AJ. Effect of digitalis on central demyelinative conduction block in vivo. Ann Neurol 1989:25: 159-65.

81. Titcombe AF, Willison RG. Flicker fusion in multiple sclerosis. J Neurol Neurosurg Psychiatry 1961:24:260-5.

82. Milner BA, Regan D, Heron JR. Differential diagnosis of multiple sclerosis by visual evoked potential recording. Brain 1974;97:755-72.

83. Celesia GG, Daly RF. Visual electroencephalographic computer analysis (VECA): a new electrophysiologic test for the diagnosis of optic nerve lesions. Neurology 1977; 27:637-41.

84. Sclabassi RJ, Namerow NS, Enns NF. Somatosensory response to stimulus trains in patients with multiple sclerosis. Electroencephalogr Clin Neurophysiol 1974:37: $23-33$

85. Uhthoff $\mathrm{W}$. Untersuchungen über die bei der multiplen Herdsklerose vorkommenden Augenströrungen. Arch Psychiatr Nervenkrankheiten 1890:21:55-116.

86. Boynton BL, Garramone PM, Buca JT. Observations on the effects of cool baths for patients with multiple sclerosis. Phys Ther Rev 1959;39:297-9.

87. Edmund J, Fog T. Visual and motor instability in multiple sclerosis. Arch Neurol Psychiatry 1955:73:316-23.

88. Nelson DA, McDowell F. The effects of induced hyperthermia on patients with multiple sclerosis. J Neurol Neurosurg Psychiatry 1959;22:113-16.

89. Symington GR, Mackay IR, Currie TT. Improvement in multiple sclerosis during prolonged induced hypothermia. Neurology 1977;27:302-3.

90. Watson CW. Effect of lowering of body temperature on the symptoms and signs of multiple sclerosis. N Engl J Med 1959:261:1253-9.

91. Galvin RJ, Regan D, Heron JR. A possible means of monitoring the progress of demyelination in multiple sclerosis: effect of body temperature on visual perception of double light flashes. J Neurol Neurosurg Psychiatry 1976;39: $861-5$.
92. Scholl GB, Song HS, Wray SH. Uhthoff's symptom in optic neuritis: relationship to magnetic resonance imaging and development of multiple sclerosis. Ann Neurol 1991; 30:180-4.

93. van Diemen HA, van Dongen MM, Dammers JW, Polman $\mathrm{CH}$. Increased visual impairment af ter exercise (Uhthoff"s phenomenon) in multiple sclerosis: therapeutic possibilities. Eur Neurol 1992;32:231-4.

94. Matthews WB. editor. McAlpine's multiple sclerosis. Edinburgh: Churchill Livingstone, 1991.

95. Hopper CL, Matthews CG. Cleeland CS. Symptom instability and thermoregulation in multiple sclerosis. Neurology 1972:22:142-8.

96. Berger JR, Sheremata WA. Reply to letter by F. A. Davis. JAMA 1985;253:203.

97. Waxman SG, Geschwind N. Major morbidity related to hyperthermia in multiple sclerosis. Ann Neurol 1983:13: 348.

98. Brickner RM. The significance of localised vasoconstrictions in multiple sclerosis. Res Publ Assoc Res Nervous Mental Dis 1950;28:236-44.

99. Davis FA. Michael JA, Tomaszewski JS. Fluctuation of motor function in multiple sclerosis related to circadian temperature variations. Dis Nervous Syst 1973:34:33-6.

100. Namerow NS. Circadian temperature rhythm and vision in multiple sclerosis. Neurology 1968;18:417-22.

101. Guthrie TC. Visual and motor changes in patients with multiple sclerosis. Arch Neurol Psychiatry 1951:65: 437-51.

102. Matthews WB. Laboratory diagnosis. In: Matthews WB, editor. McAlpine's multiple sclerosis. Edinburgh: Churchill Livingstone, 1991:189-229.

103. Davis FA. Pathophysiology of multiple sclerosis and related clinical implications. Mod Treatment 1970;7: 890-902.

104. Davis FA, Michael JA, Neer D. Serial hyperthermia testing in multiple sclerosis: a method for monitoring subclinical fluctuations. Acta Neurol Scand 1973;49:63-74.

105. Berger JR. Sheremata WA. Persistent neurological deficit precipitated by hot bath test in multiple sclerosis. JAMA 1983:249:1751-3.

106. Davis FA. Neurological deficits following the hot bath test in multiple sclerosis (letter). JAMA 1985;253:203.

107. Davis FA, Schauf CL, Reed BJ, Kesler RL. Experimental studies of the effects of extrinsic factors on conduction in normal and demyelinated nerve. J Neurol Neurosurg Psychiatry 1975;39:442-8.

108. Rasminsky M. The effects of temperature on conduction in demyelinated single nerve fibres. Arch Neurol 1973:28: 287-92.

109. Pencek TL. Schauf CL, Low PA, Eisenberg BR. Davis FA Disruption of the perineurium in amphibian peripheral nerve: morphology and physiology. Neurology 1980:30: 593-9.

110. Pender MP. Sears TA. The pathophysiology of acute experimental allergic encephalomyelitis in the rabbit. Brain 1984:107:699-726.

111. Bowe CM, Kocsis JD, Targ EF, Waxman SG. Physiological effects of 4-aminopyridine on demyelinated mammalian motor and sensory fibres. Ann Neurol 1987;22: 264-8.

112. Targ EF, Kocsis JD. Action potential characteristics of demyelinated rat sciatic nerve following application of 4-aminopyridine. Brain Res 1986:363:1 - 9

113. Targ EF, Kocsis JD. 4-Aminopyridine leads to restoration of conduction in demyelinated rat sciatic nerve. Brain Res 1985;328:358-61.

114. Bostock H, Sears TA, Sherratt RM. The effects of 4-aminopyridine and tetraethylammonium ions on normal and demyelinated mammalian nerve fibres. J Physiol (Lond) 1981:313:301-15 
115. Sherratt RM, Bostock H, Sears TA. Effects of 4-aminopyridine on normal and demyelinated mammalian nerve fibres. Nature 1980;283:570-2.

116. Jones RE, Heron JR, Foster DH, Snelgar RS, Mason RJ. Effects of 4-aminopyridine in patients with multiple sclerosis. J Neurol Sci 1983;60:353-62.

117. Stefoski D, Davis FA, Faut M, Schauf CL. 4-aminopyridine improves clinical signs in multiple sclerosis. Ann Neurol 1987;21:71-7.

118. Stefoski D, Davis FA, Tyszka MF, Schauf CL. 4-Aminopyridine improves clinical signs in multiple sclerosis. Ann Neurol 1985;18:131.

119. Davis FA, Stefoski D, Rush J. Orally administered 4-aminopyridine improves clinical signs in multiple sclerosis. Ann Neurol 1990;27:186-92.

120. van Diemen HA, Polman CH, Koetsier JC, van Loenen AC, Nauta JJ. 4-aminopyridine in patients with multiple sclerosis: dosage and serum level related to efficacy and safety. Clin Neuropharmacol 1993;16:195-204.

121. Schocpfle GM, Erlanger J. The action of temperature on the excitability, spike height and configuration and the absolute refractory period observed in the responses of single medullated nerve fibres. Am J Physiol 1941:134: 694-704.

122. Davis FA, Becker FO, Michael JA, Sorensen E. Effect of intravenous sodium bicarbonate, disodium edetate ( $\mathrm{Na}$,EDTA), and hyperventilation on visual and oculomotor signs in multiple sclerosis. J Neurol Neurosurg Psychiatry $1970 ; 33: 723-32$

123. Rasminsky M. Spontaneous activity and cross-talk in pathological nerve fibres. Res Publ Assoc Res Nervous Mental Dis $1987 ; 65: 39-49$

124. Waxman SG, Kocsis JD, Eng DL. Ligature-induced injury in peripheral nerve: electrophysiological observations on changes in action potential characteristics following blockade of potassium conductance. Muscle Nerve 1985;8: 85-92.

125. Rasminsky M. Hyperexcitability of pathologically myelinated axons and positive symptoms in multiple sclerosis. In: Waxman SG, Ritchie JM, editors. Advances in neurology, vol. 31. Demyelinating disease: basic and clinical electrophysiology. New York: Raven Press, 1981:289-97.

126. Howe JF, Loeser JD, Calvin WH. Mechanosensitivity of dorsal root ganglion and chronically injured axons: a physiological basis for the radicular pain of nerve root compression. Pain 1977;3:25-41.

127. Huizar P, Kuno M, Miyata Y. Electrophysiological properties of spinal motoneurones of normal and dystrophic mice. J Physiol (Lond) 1975;248:231-46.

128. Rasminsky M. Spontaneous activity and cross-talk in pathological nerve fibres. In: Kandel ER, editor. Molecular neurobiology in neurology and psychiatry. New York: Raven Press, 1987:39-49.

1.29. Rasminsky M. Ectopic generation of impulses and crosstalk in spinal nerve roots of 'dystrophic' mice. Ann Neurol 1978;3:351-7.

130. Smith KJ, McDonald WI. Spontaneous and evoked electrical discharges from a central demyelinating lesion. J Neurol Sci 1982;55:39-47.

131. Smith KJ, McDonald WI. Spontaneous and mechanically evoked activity due to a central demyelinating lesion. Nature 1980;286:154-5.

132. Lhermitte $\mathrm{J}$, Bollack $\mathrm{J}$, Nicholas $\mathrm{M}$. Les douleurs à type de décharge éléctrique consécutives à la flexion céphalique dans le sclérose en plaque. Rev Neurol 1924;2:56-62.

133. Kanchandani R, Howe JG. Lhermitte's sign in multiple sclerosis: a clinical survey and review of the literature. J Neurol Neurosurg Psychiatry 1982;45:308-12.

134. Davis FA, Bergen D, Schauf C, McDonald I, Deutsch W. Movement phosphenes in optic neuritis: a new clinical sign. Neurology 1976;26:1100-4.
135. Rasminsky M. Ephaptic transmission between single nerve fibres in the spinal nerve roots of dystrophic mice. J Physiol (Lond) 1980;305:151-69.

136. Kapoor R, Smith KJ, Felts PA, Davies M. Internodal potassium currents can generate ectopic impulses in mammalian myelinated axons. Brain Res 1993;611:165-9.

137. Kapoor R, Felts PA, Smith KJ. A mechanism for ectopic bursts of impulses in central demyelinated axons. Ann Neurol 1993;34:271.

138. Young W, Rosenbluth J, Wojak JC. Sakatani K, Kim H. Extracellular potassium activity and axonal conduction in spinal cord of the myelin-deficient mutant rat. Exp Neurol 1989;106:41-51.

139. Prineas JW, Connell BS. The fine structure of chronically active multiple sclerosis plaques. Neurology 1978; 28(Suppl):68-75.

140. Namerow NS. The pathophysiology of multiple sclerosis. In: Wolfgram F, Ellison GW. Stevens JG, et al. editors. Multiple sclerosis: immunology, virology and ultrastructure. New York: Academic Press, 1972:143-72.

141. Cerf JA, Carels G. Multiple sclerosis: serum factor producing reversible alterations in bioelectric responses. Science 1966;152:1066-8.

142. Rose AS. Demyelinating disease: clinical features. In: Rose AS, Pearson CM, editors. Mechanisms of demyelination. New York: McGraw-Hill, 1963:199-217.

143. Schauf CL, Davis FA. Circulating toxic factors in multiple sclerosis: a perspective. Adv Neurol 1981;31:267-80.

144. Hoffman PM, Gaston DD, Spitler LE. Comparison of experimental allergic encephalomyelitis induced with spinal cord, basic protein, and synthetic encephalitogenic peptide. Clin Immunol Immunopathol 1973;1:364-71.

145. Lassmann H, Wisniewski HM. Chronic relapsing experimental allergic encephalomyelitis: effect of age at the time of sensitization on clinical course and pathology. Acta Neuropathol 1979;47:111-6.

146. Panitch $\mathrm{H}$, Ciccone $\mathrm{C}$. Induction of recurrent experimental allergic encephalomyelitis with myelin basic protein. Ann Neurol 1981;9:433-8.

147. Raine CS, Traugott U, Farooq M, Bornstein MB, Norton WT. Augmentation of immune-mediated demyelination by lipid haptens. Lab Invest 1981;45:174-82.

148. Simmons RD, Bernard CC, Ng KT, Carnegie PR. Hindlimb motor ability in Lewis rats during the onset and recovery phases of experimental autoimmune encephalomyelitis. Brain Res 1981;215:103-14.

149. Kerlero de Rosbo N, Bernard CC, Simmons RD, Carnegie PR. Concomitant detection of changes in myelin basic protein and permeability of blood-spinal cord barrier in acute experimental autoimmune encephalomyelitis by electroimmunoblotting. J Neuroimmunol 1985;9:349-61.

150. Levine S, Sowinski R, Shaw CM, Alvord EC Jr. Do neurological signs occur in experimental allergic encephalomyelitis in the absence of inflammatory lesions of the central nervous system? J Neuropathol Exp Neurol 1975; 34:501-6

151. Bieger D. White SR. Anatomical evidence for bulbospinal monoamine axon damage in rats with experimental allergic encephalomyelitis. Neuroscience 1981;6:1745-52.

152. Smith KJ, Hall SM. Nerve conduction during peripheral demyelination and remyelination. J Neurol Sci 1980;48: 201-19.

153. Pender MP. Conduction block due to demyelination at the ventral root exit zone in experimental allergic encephalomyelitis. Brain Res 1986;367:398-401.

154. Pender MP. Demyelination and neurological signs in experimental allergic encephalomyelitis. J Neuroimmunol 1987;15:11-24.

155. Pender MP. Recovery from acute experimental allergic encephalomyelitis in the Lewis rat: early restoration of 
nerve conduction and repair by Schwann cells and oligodendrocytes. Brain 1989;112:393-416.

156. Pender MP. The pathophysiology of myelin basic proteininduced acute experimental allergic encephalomyelitis in the Lewis rat. J Neurol Sci 1988;86:277-89.

157. Prineas JW, Barnard RO, Kwon EE, Sharer LR, Cho ES. Multiple sclerosis: remyelination of nascent lesions. Ann Neurol 1993;33:137-51.

158. Prineas JW, Kwon EE, Goldenberg PZ, Cho E-S, Sharer LR. Multiple sclerosis: destruction of proliferating oligodendrocytes and new myelin in developing lesions. J Neuropathol Exp Neurol 1987;43:366.

159. Bornstein MB, Crain SM. Functional studies of cultured brain tissues as related to 'demyelinative disorders'. Science 1965;148:1242-4.

160. Carels G, Cerf JA. Reversible depression of the reflex activity of the isolated spinal cord of the frog by the blood of patients with multiple sclerosis (French). Rev Neurol 1966;1 15:242-9.

161. Carels G, Cerf JA. Functional alterations produced in an isolated nerve centre by serum from patients with multiple sclerosis. Int Arch Allergy Appl Immunol 1969;36 (Suppl):608-28

162. Lumsden CE, Howard L, Aparicio SR. Anti-synaptic antibody in allergic encephalomyelitis. I. Neurophysiological studies, in guinea pigs, on the exposed cerebral cortex and peripheral nerves, following immunological challenges with myelin and synaptosomes. Brain Res 1975;93: 267-82.

163. Lumsden CE, Howard L, Aparicio SR, Bradbury M. Antisynaptic antibody in allergic encephalomyelitis. II. The synapse-blocking effects in tissue cuiture of demyelinating sera from experimental allergic encephalomyelitis. Brain Res 1975;93:283-99.

164. Schauf CL, Davis FA, Sack DA, Reed BJ, Kesler RL. Neuroelectric blocking factors in human and animal sera evaluated using the isolated frog spinal cord. J Neurol Neurosurg Psychiatry 1976;39:680-5.

165. Schauf CL, Schauf V, Davis FA, Mizen MR. Complementdependent serum: neuroelectric blocking activity in multiple sclerosis. Neurology 1978;28:426-30.

166. Schauf CL, Davis FA. The occurrence, specificity, and role of neuroelectric blocking factors in multiple sclerosis. Neurology 1978;28:34-9.

167. Seil FJ, Leiman AL, Kelly JM. Neuroelectric blocking factors in multiple sclerosis and normal human sera. Arch Neurol 1976;33:418-22.

168. Seil FJ, Smith ME, Leiman AL, Kelly JM. Myelination inhibiting and neuroelectric blocking factors in experimental allergic encephalomyelitis. Science 1975;187: 951-3.

169. Seil FJ, Smith MF, Leiman AL, Kelly JM III. Myelination inhibiting and neuroelectric blocking factors in experimental allergic encephalomyelitis. Science 1975;187: 951-3.

170. Crain SM, Bornstein MB, Lennon VA. Depression of complex bioelectric discharges in cerebral tissue cultures by thermolabile complement-dependent serum factors. Exp Neurol 1975;49:330-5.

171. Schmutz M, von Hahn HP, Honegger CG. Effect of multiple sclerosis serum on ventral root responses in isolated frog spinal cord. Eur Neurol 1977;15:345-51.

172. Schauf CL, Antel JP, Arnason BG, Davis FA, Rooney MW. Neuroelectric blocking activity and plasmapheresis in amyotrophic lateral sclerosis. Neurology 1980;30: 1011-3.

173. Seil FJ. Tissue culture studies of neuroelectric blocking factors. Adv Neurol 1981;31:281-8.

174. Seil FJ. Tissue culture studies of demyelinating disease: a critical review. Ann Neurol 1977;2:345-55.
175. Stefoski D, Schauf CL, McLeod BC, Haywood CP, Davis FA. Plasmapheresis decreases neuroelectric blocking activity in multiple sclerosis. Neurology 1982;32:904-7.

176. Bornstein MB, Appel SH. The application of tissue culture to the study of experimental 'allergic encephalomyelitis'. I. Patterns of demyelination. J Neuropathol Exp Neurol 1961;20:141-57.

177. Appel SH, Bornstein MB. The application of tissue culture to the study of experimental allergic encephalomyelitis. II. Serum factors responsible for demyelination. Exp Med 1964:119:303-12.

178. McDonald WI, Miller DH, Barnes D. The pathological evolution of multiple sclerosis. Neuropathol Appl Neurobiol 1992;18:319-34.

179. Sawada M, Hara N, Ichinose M. Interleukin-2 inhibits the GABA-induced C1-current in identified Aplysia neurons. J Neurosci Res 1992;33:461-5.

180. Sawada M, Hara N, Maeno T. Analysis of a decreased $\mathrm{Na}^{+}$ conductance by tumour necrosis factor in identified neurons of Aplysia kurodai. J Neurosci Res 1991;28:466-73.

181. Sawada M, Hara N, Maeno T. Ionic mechanism of the outward current induced by extracellular ejection of interleukin-l onto identified neurons of Aplysia. Brain Res 1991; 545:248-56.

182. Sawada M, Hara N, Maeno T. Reduction of the acetylcholine-induced $\mathrm{K}^{+}$current in identified Aplysia neurons by human interleukin-1 and interleukin-2. Cell Mol Neurobiol 1992;12:439-45.

183. Brinkmeier H, Kaspar A, Wietholter H, Rudel R. Interleukin-2 inhibits sodium currents in human muscle cells. Pflugers Arch 1992;420:621-3.

184. Szucs A, Stefano GB, Hughes TK, Rozsa KS. Modulation of voltage-activated ion currents on identified neurons of Helix pomatia L. by interleukin-1. Cell Mol Neurobiol 1992; 12:429-38.

185. ffrench-Mullen JMH, Plata-Salaman CR. Interleukin-1 beta inhibition of calcium channel currents in isolated hippocampal CA1 neurons: pharmacology and mode of action Soc Neurosci Abstr 1992;188.10.

186. Plata-Salaman CR, ffrench-Mullen JMH. Interleukin-1 beta inhibits calcium channel currents in isolated hippocampal CAl neurons Soc Neurosci Abstr 1992;188.9.

187. Smith KJ, Blakemore WF, Murray JA, Patterson RC. Internodal myelin volume and axon surface area. A relationship determining myelin thickness? J Neurol Sci 1982;55: 231-46.

188. Blakemore WF, Murray JA. Quantitative examination of internodal length of remyelinated nerve fibres in the central nervous system. J Neurol Sci 1981;49:273-84.

189. Hines M, Shrager P. A computational test of the requirements for conduction in demyelinated axons. Restor Neurol Neurosci 1991;3:81-93.

190. Blakemore WF, Eames RA, Smith KJ, McDonald WI. Remyelination in the spinal cord of the cat following intraspinal injections of lysolecithin. J Neurol Sci 1977;33: 31-43.

191. Prineas JW, Connell F. Remyelination in multiple sclerosis. Ann Neurol 1979;5:22-31.

192. Prineas JW, Kwon EE, Sharer LR, Cho E-S. Massive early remyelination in acute multiple sclerosis. Neurology 1987; 37 (Suppl 1): 109.

193. Waxman SG. Molecular and cellular organisation of the central nervous system: implications for new therapeutics. Res Publ Assoc Res Nervous Mental Dis 1993;71:1-21.

194. Hille B. Ionic channels of excitable membranes. Sunderland, Massachusetts: Sinauer, 1992. 